\title{
Challenging prevailing narratives with Twitter: An \#AustraliaDay case study of participation, representation, and elimination of voice in an archive
}

Pamela Fransen-Taylor and Bhuva Narayan

University of Technology Sydney

\begin{abstract}
Social Media, specifically a microblogging service such as Twitter, is a public space that has changed how we interact with, exchange, and respond to information in a civil society. It also has the potential to give public voice to minority narratives that are under-represented in the mainstream media, just as grassroots graffiti in public spaces has done over human history. Using a specific case study around an issue in the Australian national discourse around Australia Day, this study contributes new insights towards an understanding of how alternate narratives are expressed and erased in cyberspace, just as graffiti is erased from public view by the authorities. Widely promoted by official sources as a day of festivity and celebration, the Australia Day Your Way initiative actively promotes the use of the hashtag \#AustraliaDay to metatag tweets for capture to an annual time capsule stored by the National Museum of Australia. For Australia's indigenous minority though, Australia Day is symbolic of an entirely different narrative, expressed online through the hashtags \#InvasionDay and \#SurvivalDay. We studied all three hashtags and their intersections on Twitter and also compared this data to what was showcased in the official time capsule. We found that although the alternative voices existed on Twitter, they were excluded from the official time capsule. This has implications for both archives and for future historians studying contemporary events.
\end{abstract}

\section{Keywords}

Twitter, social media, digital material, preservation, selection, cultural narratives, graffiti, Australia Day

\section{Introduction}

Social Media has changed how we interact with, exchange, and respond to information in a civil society. When information is considered a social construct, where meaning is negotiated though discourse, it becomes particularly important to consider whether all aspects of the discourse are afforded a free voice. This has implications not only on social media itself, but also in the way LIS professionals use, represent, or collect social media information as part of their professional practice, for when some voices are afforded more or less value than others, or when certain voices are muted, inequality regimes (Acker, 2006) arise. Additionally, in 
privileging textual, published and traditional sources of information over social media, information service providers may inadvertently silence the voice of people from marginalised communities that may only exist on emerging new media and online communities.

Adopting the position that Twitter and other social media data constitute a new form of documentary artefact that 'present evidence of contemporary life that should be collected and maintained for their historic value as part of society's memory' (Henninger and Scifleet, 2016: 277) this paper reviews the key issues discussed in the relevant LIS and related literature pertaining to digital selection, digital curation, and cultural heritage preservation and how the rise of participatory culture and big data are contributing to an increasingly complex set of collection issues; this is achieved through a specific case study around an ongoing public discourse in Australia. The research question driving the study was: Are alternate voices and narratives around Australia Day represented on social media, and how are cultural institutions collecting and presenting these voices?

Widely promoted by official sources as a day of festivity and celebration, the Australia Day Your Way initiative was started in 2014 and actively promotes the use of the hashtag \#AustraliaDay to metatag tweets for capture to an annual time capsule stored by the National Museum of Australia. For Australia's indigenous minority though, Australia Day is symbolic of an entirely different narrative, one of oppression and loss, and entirely in contrast to the one celebrated in the mainstream. Hence, by examining the \#InvasionDay and \#SurvivalDay hashtags on Twitter that are used to contest the mainstream narrative (alongside the official \#AustraliaDay hashtag), this study identified the presence of an active community online contesting the prevailing narrative. Despite the continual presence of these alternate voices on Twitter, our findings show that this alternate narrative was excluded from the official time capsule. This has implications for both archives and future historians studying contemporary events.

\section{Background}

'Social media have changed the way we conceptualise the boundaries of space and time as well as how we interact with, exchange and respond to information. As a result, information behaviour is evolving alongside digital social media technologies. Increasingly, individuals and organisations are turning to social media to find as well as to disseminate information' (Fransen-Taylor \& Narayan, 2016:1).

Since the announcement in 2010 that Twitter was donating its complete digital archive of public tweets to the Library of Congress (LOC), along with establishing an ongoing transfer of posts, the digital research community has waited with much anticipation for further news regarding when and how they might get access to this archive of anthropological data. In December 2017 LOC instead announced that commencing in 2018 it would be scaling back the archive to include a sampling of only a very select set of 'thematic and event-based [tweets], including events such as elections, or themes of ongoing national interest, e.g. public policy' (Osterberg, 2017). Social media researchers and commentators as well as journalists were quick to voice their concerns (Alaimo, 2017; Bruns, 2018; Leetaru, 2017) regarding political accountability at a time when politicians are increasingly using Twitter to make un-vetted public statements, while others have suggested the library has never had a plan for how to make all or part of the data available, nor budget to do so, that Twitter has not 
furnished the library with distribution rights, nor could it be in their commercial interests to enable free access to a complete Twitter archive (Shulman, 2018).

Following these emerging social media data collection and curation issues, this article relates the findings of a pilot study designed to explore cultural narratives through a professionally curated Twitter archive at the National Museum of Australia where mainstream social rituals dominate, and alternate perspectives are marginalised; this has implications for archives and for future historians. Additionally, drawing an analogy between graffiti (and how it is treated by mainstream society) and Twitter posts, the qualities of social media as a form of new media that enables non-institutional political participation are explored. With this lens we look at how Twitter has been used to enact resistance against the dominant celebratory narrative associated with Australia Day in order to highlight a discernable bias associated with the establishment of a professionally curated Twitter time capsule at the National Museum of Australia destined to stand as a significant cultural memory artefact. In doing so the authors aim to contribute to the debate amongst LIS practitioners regarding how best to service the needs of current and future users while continuing to navigate the issues associated with social media data and social media archives.

\section{Social Media Content as Documents of Contemporary Society}

Kaplan and Haenlein define social media as 'a group of Internet-based applications that build on the ideological and technological foundations of Web 2.0, and which allow the creation and exchange of user generated content' (Kaplan and Haenlein, 2010: 61); this term encompasses a large range of applications and platforms including blogs (short for web logs), collaborative projects such as wikis, content communities such as YouTube, Flickr, and Tumblr, social networking sites such as Facebook and Twitter, and virtual game worlds and virtual social worlds such as Second Life. Boyd and Ellison have suggested that social networks 'support the maintenance of pre-existing social networks [as well as] help strangers connect based on shared interests, political views, or activities' (2008: 210). Indisputably, social media is now 'a shared and lived in space that spans most of the world and is influencing many aspects of our lives' (Narayan, 2013: 33).

In recent times, scholars have turned their attention to exploring the potential of information and communications technologies (ICT), specifically social media, as enablers for civil society (Mehra et al., 2004; Naughton, 2001; Koepfler and Hansen, 2012; Gurstein, 2003). While some have identified access inequalities such as the digital divide, along with 'government regulation or censorship, and aggressive corporate action' (Naughton, 2001: 147) as potential hindrances, effective use is seen as a means to facilitating social inclusion and participation by minorities and marginalised citizens in mainstream society (Gurstein, 2003; Koepfler and Hansen, 2012). Social media has become a recognised form of online behaviour (Acker and Kriesberg, 2017) with the results producing increasingly significant social documents (Scifleet et al., 2013). These documents of society are as worthy of curation and archiving in cultural institutions as any other document relevant to understanding society.

\section{Microblogging as a new form of communication}

Twitter, launched in July 2006, is a social networking site and micro blogging service that allows people to post or send short (140 character) messages known as 'tweets'. Twitter differs from other social networking sites such as Facebook in that it does not require the user to have existing social connections with people. Instead it enables users to follow or be 
followed by people they may or may not know, or even follow conversations based on a hashtag, without having a Twitter account (Bruns and Burgess, 2015). The number of users active on Twitter on a daily basis is estimated to be 100 million, with an average of 500 million tweets sent per day (Aslam, 2018). In addition to accessing Twitter via the Internet (www.Twitter.com), Twitter supports sending and receiving tweets via SMS from a mobile device enabling both synchronous and asynchronous use.

According to Bruns and Burgess, Twitter features and conventions have largely evolved through 'user-led innovations [such as] the @ reply format for addressing or mentioning fellow users, the integration of multimedia [and] the hashtag' (2011:2). A retweet, usually indicated with an 'RT' prefix before reposting another user's tweet, may indicate a form of agreement or endorsement and 'empowers users to spread information of their choice beyond the reach of the original tweet's followers' (Kwak et al., 2010: 591).

\section{Hashtags as communication affordances}

Hashtags enable users to participate in topic-based conversations (Moorley and Chinn, 2014) by embedding searchable metadata references within the body of a tweet, creating a 'folksonomy' (Zappavigna, 2011). Hashtags are used to refer to people, places, and entities, and can also represent emotions, for example \#happy, \#depressed and \#hungry. They can come into existence spontaneously, in response to real-time, breaking news, emergencies, or disasters such as \#sydneyseige, \#jesuischarlie, \#mh370, or be more deliberately appointed, to promote specific planned events like \#australiaday or \#oscars. (Bruns and Burgess, 2015; Giglietto and Lee, 2017). When hashtags 'coordinate public discussion and information sharing on news and political topics' (Bruns and Burgess, 2011:3) they '...facilitate conversation amongst unconnected individuals, resulting in an important form of digital political communication and behaviour' (Bode et al., 2015: 152). The speed with which hashtags can come into being in response to emerging issues allows them to facilitate the formation of ad hoc publics. In such instances, the bottom-up nature of the process makes it particularly difficult for any particular institution to 'dominate the conversation' (Bruns and Burgess, 2011: 7).

\section{Cultural Heritage Institutions and Web 2.0}

Early discussions of Web 2.0 in LIS literature centered around the use of new Internet based technologies to provide new and more engaging services for users, while the Library 2.0 movement sought to service virtual communities (Weaver, 2007). Deodato (2014) also discusses how users can deposit their own work into electronic libraries where it can be preserved and made accessible to the community. This assumes an academic or formal authorship, which also advocates for training users in how to contribute to collections (Deodato, 2014: 750). We would argue that many social media users are already savvy about their contributions to the ad-hoc publics, and that this article fails to recognise the materials of participatory culture as worthy of collection.

\section{Digital Selection and Preservation of Social Media Content}

Ravenwood, Matthews, and Muir (2013) identified six organisational areas of concern in the selection and preservation of digital materials in libraries: resources and volume; criteria; policy; legal and ethical issues; roles and responsibility; and user aspects of selection. 
Additionally, the very nature of digital materials challenges traditional methods of selection (Ravenwood, Muir, and Matthews (2015). Previous literature in this space mainly discusses the digitisation of non-digital objects (Evens and Hauttekeete, 2011). In regard to the selection and preservation of tweets, Arnold and Sampson (2014) discuss issues around provenance as well as how the method of capture by application level programs (using application programming interfaces (APIs)) produce different result sets from Rest API Search commands. Other technological challenges include technology obsolescence, intellectual property issues, institutional business models, and lack of funding (Evens and Hauttekeete, 2011). SalahEldeen and Nelson (2012) bemoan the loss of much of social media data before researchers have even realised their value. Contemporary techniques focusing on scraping data from webpages can be quite rapid; however, platform-specific layout, and important contextual components may be lost in the process of employing scraping methods(Acker and Kriesberg, 2017: 2).

\section{Case Study of \#AustraliaDay Tweets}

Since 2014, the Australia Day Council (NADC), the National Museum of Australia (NMA) and Twitter have jointly promoted an annual Australia Day Your Way campaign, with the stated intention of creating a digital time capsule around the national holiday. This campaign encourages all Australians to post tweets in conjunction with the hashtag \#AustraliaDay, to illustrate the way citizens choose to mark the day. This promotion of a specific hashtag, combined with the observance of national holiday on the date of the arrival of the British first fleet at Port Jackson, New South Wales and the subsequent colonization of Australia represents a very specific cultural narrative. However, the unintended ad-hoc publics created through this Australia Day hashtag, and the preservation of the corpus of tweets it created, is the main subject of our case study.

While various studies have investigated the power of social media to enact change against political oppression (Tufekci and Wilson, 2012; Lim, 2012; Shirky, 2011), little is known about how cultural narratives are contested in online spaces and whether social media offers an equitable place in which to voice stories usually silenced by the power of a cultural majority. In response, this study explored the act of 'tweeting' as a form of written public address employed by minority groups to challenge prevailing cultural narratives. Graffiti research is adopted as a lens with which to focus our exploration, in order to understand the circumstances under which minorities have employed informal writing to enact resistance. In doing so, the conceptualisation of graffiti and graffiti writing has been extended beyond the bounds of physical space. Graffiti is used as a metaphor for tweets which are marked on the walls constructed by Twitter, held in place by hashtags. The results of this study also show how these tweets that challenge prevailing narratives are treated in a similar manner to graffiti in public spaces, in that they are erased from public view.

\section{The Concept of Tweets as Graffiti}

The concept of tweets as graffiti was originally inspired by a 2015 Australia Day quote by the then Australian Prime Minister who declared that 'Social media is kind of like electronic graffiti and I think that in the media, you make a big mistake to pay too much attention to social media' (Snowden, 2015), but in the words of one Twitter user, '\#Electronicgraffiti is 
real democracy; people working together for the common good; ...\#SurvivalDay' (squig, 2015).

Social researchers have identified graffiti as a form of written resistance, which arises when social equality is absent, or when those on the boundaries of society feel unable to find an alternative means for expression. Graffiti provides a mechanism with which to interject their voices into an otherwise unapproachable public discourse. The term graffiti originates from the Greek word 'graphein' meaning to 'mark, draw, write', and is the plural form of the Italian word 'graffito' which refers to 'a scratch' (Macquarie Dictionary, 1995: 401). Graffiti are drawings or words etched into or marked on walls (Whitehead, 2004) in either public (fences, the outside of buildings, public transport) or private (within buildings) locales (Rodriguez and Clair, 1999). Scholars that study the phenomenon of graffiti do so as a means of gaining insight into cultural customs and attitudes (Stocker et al., 1972; Abel and Buckley, 1977). Abel and Buckley describe graffiti as 'a form of communication that is both personal and free of the everyday social restraints that normally prevent people from giving uninhibited reign to their thoughts' (1977: 3) due to its largely anonymous nature.

Chaffee suggests that 'when various public discourses are officially and oppressively muted by government officials, graffitists consistently resort to public walls to hold such discourses' (in Rodriguez and Clair, 1999: 3). In so doing, graffitists 'enact identity, resistance, and oppression' amongst diverse groups (Rodriguez and Clair, 1999). Themes in graffiti include politics (Peteet, 1996; Hanauer, 2011), race, gender, and sexual orientation (Stocker et al., 1972; Rodriguez and Clair, 1999). Graffiti is also used as a way to say, 'I am here, this is MY view of the world and this is where I see myself in that world' (Bowen, 2010: 3). Scheibel's study of film school graffiti demonstrates the discursive nature of graffiti which he suggests is not 'merely individual expressions; rather, graffiti communicatively constitute and reconstitute a collectively created social reality' (1994: 3).

We are particularly interested in what Gadsby describes as cultural graffiti research, where graffiti is treated as 'a representation of a specific community or group' (1995: 2). Graffiti research of this type is less interested in the individual graffitist, focusing instead on contextual and cultural factors in order to 'illustrate the collective everyday life and feelings of the people of that particular culture' (1995: 2). Social or cultural conflict is often the impetus for political graffiti. Sociologists describe two forms of political participation; institutional and non-institutional. Institutional political participation is used to describe formal processes such as attending caucus and voting. Graffiti falls into the category of noninstitutional political participation, which describes protests, demonstrations and other forms of action seen to be 'norm-violating, stigmatized, and subject to social control' (Waldner and Dobratz, 2013: 377).

Chaffee's study of politically motivated public art in the Basque region of Spain and France found that the medium 'facilitates grass-roots participation' (1988: 546) on such a broad scale as to qualify as an alternative form of mass-communication by 'sharing information with the public, teaching people about necessary and useful matters, and building support for ideas and activities' (Chaffee, 1988: 547). Hanauer's discourse analysis of graffiti on the wall of Abu Dis illustrated the importance of language in defining the significance of the wall from 'a series of political positions' (2011: 316). Sometimes, defacing public property can be as much about the message as it is about the 'location or the context in which graffiti is created' (Waldner and Dobratz, 2013: 379). Situating graffiti in specific locations can be a deliberate 
act to appropriate a cultural space (Waldner and Dobratz, 2013). Cultural space though, is nolonger necessarily defined by spatial and temporal parameters. 'Social media...create opportunities for the discursive construction of hybridized cultures... [in which] individuals can use social media to create new virtual cultural spaces' (McEwan and Sobre-Denton, 2011: 252). It is also true that graffiti that is considered vandalism by authorities in its time may come to be considered as art under different circumstances or by the people that the graffiti speaks for.

Examining tweets as a social phenomenon analogous to graffiti can also provide us with a valuable insight into human information behaviours. Tuominen and Savolainen describe information behaviour as discursive action (1997), which involves people interacting with and through symbols such as language (Veinot and Williams, 2012) where information forms "a property of conversation" (Taylor (1993) cited in Pettigrew, 1999: 811). If the question of 'how to foster and develop social interactions which will lead to a strong and inclusive society' (Onyx et al., 2011: 47) is at the heart of achieving equity for all citizens, a greater understanding of human information behaviour as a core component of the "human communication process" (Pettigrew et al., 2001: 67) is required.

\section{Australia and the National Discourse Around Australia Day}

According to 2011 census data, Australia's population was approximately 21.5 million people, of which 548,369 or 2.5\% identified as Aboriginal or Torres Strait Islanders (Australian Bureau of Statistics, 2011). Until the first half of the twentieth century, Australia could 'readily be defined as 98 per cent British' (Jones, 2000: 176). In 1973, with the official abolition of the White Australia policy, Australia declared itself a multicultural nation. According to the Australian Bureau of Statistics, in 2006, 4.4 million Australians or one quarter of the population, were born overseas; the most common birthplace among them was the United Kingdom at 24\%, followed by New Zealand at $9 \%$ and China and Italy around 5\% each (2006). In 1999 an Australian referendum proposing 'To alter the Constitution to establish the Commonwealth of Australia as a republic with the Queen and Governor-General being replaced by a President appointed by a two-thirds majority of the members of the Commonwealth Parliament' (Australian Electoral Commission, 2012) was not carried, with Australia remaining a Constitutional Monarchy.

The Prevailing Australia Day Narrative

On $26^{\text {th }}$ January 1788 , the First Fleet of eleven convict ships from Great Britain, commanded by Captain Arthur Phillip, arrived at Sydney Cove (National Australia Day Council 2015c). Since 1984, this date has been observed as 'Australia Day', officially marked as a National Day of celebration incorporating Australian of the Year awards bestowed, by The Prime Minister, Order of Australia awards (in Civil and Military Divisions), citizenship and affirmation ceremonies (Australian Government, 2015; National Australia Day Council 2015c). Numerous localised events aimed at bringing Australians together to "celebrate what's great about Australia and being Australian' (National Australia Day Council 2015b) are also hosted. Australia's national flag, featuring the Union Jack, the Commonwealth Star and the Southern Cross, is a prominent feature in Australia Day celebrations.

Commencing in 2014, the National Australia Day Council (NADC), the National Museum of Australia (NMA) and Twitter launched an annual Australia Day Your Way initiative encouraging all Australians to post tweets using the hashtag \#AustraliaDay, to illustrate the 
way citizens choose to mark the day, for capture to a Twitter time capsule. In 2015 more than 130,000 Tweets using \#AustraliaDay were created, with the NMA curating 4000 for a live online exhibition, accessible at http://www.your.australiaday.org.au. Australian flags, beaches, water sports, native animals, barbeques, food, and backyard cricket are repetitive themes. Symbols of celebration and community cohesion with congenial captions and messages prevail.

Indigenous Australians' Opposition to the Date of Australia Day

In 1988, the Bicentenary of the arrival of the First Fleet, Aboriginal Australians declared their opposition to the 26th January Australia Day celebrations, labelling it 'Invasion Day', and made a statement through protest concerts and marches. Protests featured posters that expressed that dissent: 'WHITE AUSTRALIA HAS A BLACK HISTORY — DON'T CELEBRATE 1988'; 'AUSTRALIA DAY = INVASION DAY 1988'" (National Australia Day Council 2015a). As a hunter-gatherer people, Indigenous Australians are estimated to have lived on the land for between 40,000 - 60,000 years prior to European settlement. The arrival of the First Fleet symbolises the beginning of great upheaval to Aboriginal culture and traditions. According to Dockery (2010), their way of life has been irreversibly affected by the 'emergence of Western society as the dominant culture' (Dockery, 2010: 315), which has in turn resulted in persistent inequality and living standards disparity between non-Indigenous and Indigenous Australians. Jones (2000) suggests that while social and material conditions have improved as a result of the growth of Aboriginal activism since the 1960s, Indigenous Australians 'remain the most disadvantaged group in Australian Society' (Jones, 2000: 176).

The arguments of 'self-determination' versus 'assimilation' present complex issues for citizens and policy makers alike; 'equity' measured according to socio-economic outcomes such as income, employment, and education, are dominated by a Western values system. 'Implicit in this tension is the view that attachment to traditional culture and lifestyles is a hindrance to the achievement of 'mainstream' economic goals' (Dockery, 2010: 316). Though it goes beyond the scope of this paper to explore, attempts to address Indigenous disadvantage have thus far failed to achieve an acceptable outcome for the welfare of Australia's Indigenous people. Our research sits within this issue, and the tension between the mainstream Australian discourse and the hurt and anger felt by Australian indigenous people in regard to Australia Day, with some of them old enough to remember the re-enactment of the landing of the First Fleet that was staged during the state-level Australia Day celebrations until 1988 (Darian-Smith, 2017).

\section{Methodology}

The vast quantities of data generated by social media, combined with the dynamic nature of its form, can present significant 'methodological challenges' (Siapera, 2014: 544). For the purposes of this study, we downloaded a sample set of data, which might reasonably be expected to return sentiments from one or more non-prevailing narratives. Cognizant of the Australia Day Council's request for \#AustraliaDay tweets, this hashtag, along with tweets consisting of two related but contentious hashtags, namely; \#InvasionDay and \#SurvivalDay, were collected; naturally, there was a lot of overlap within single tweets that used all three hashtags in one tweet. While the Twitter API can be used to create live tweet feeds, Twitter policy prevents the download of tweets greater than one week old. In this instance data was 
purchased via Sifter, an application developed by Prof. Stuart Shulman at Texifter (http://sifter.texifter.com).

The tweets were loaded into Cloud-based software DiscoverText, which provided tools to produce both descriptive statistics such as the number of tweets, most frequently used hashtags, and most active users. DiscoverText was also used to perform qualitative content analysis, enabling the development of a set of thematic codes to explain the tweets collected.

\section{Ethical Considerations}

In our contemporary society, groups, individuals, and organisations alike use social media to produce and share large quantities of information online. While components of this data can be considered a discourse in the public sphere, considerable amounts of this data are the substance of private conversations between individuals. The challenge for researchers is constructing appropriate ethical boundaries when 'social media brings together different social spheres, [making] a range of personal data from those spheres searchable and visible' (Trottier, 2011).

The public campaign to promote the use of \#AustraliaDay as a mechanism to have individual tweets gathered in the annual time capsule that is accessible in the public sphere may negate user expectations of privacy, although not everyone using the hashtag \#AustraliaDay may be aware of this campaign. On the other hand, even among those aware of the campaign, using \#SurvivalDay and \#InvasionDay in their tweets (unless combined with \#AustraliaDay), may not result in the same expectations. As such, we considered the de-identification of the data from this research however considering the proactive and political nature of these hashtags, and the interest of this study in representing diverse voice in an equitable manner, we decided that paraphrasing tweets to prevent their retrieval through online searches would not only be a form of intervention in the political process but can also be considered a form of censorship and erasure of voice. To this end, Twitter users have not been de-identified and their tweets remain in their original form in this paper.

\section{Delimitations and Limitations}

Twitter was selected over alternate social networking sites due to the Australia Day Your Way promotion on Twitter as the space in which the \#AustraliaDay conversation would be captured. Having been promoted by a national cultural organisation, it offered an ideal opportunity to observe the participation of voices in a cultural conversation online. Different events and social media sites might yield different results, as might the use of different hashtags. Case study research has limited generalisability (Bryman, 2012) and as such findings are limited to the community and events specifically analysed.

\section{Data Source}

The data was collected using the hashtags \#AustraliaDay, \#InvasionDay and \#SurvivalDay within a date range of $25^{\text {th }}-27^{\text {th }}$ January 2015, around the Australia Day events on $26^{\text {th }}$ January 2015. This yielded a total of 110,947 (58,099 unique) tweets. Of this collection, 11,182 tweets contained either \#InvasionDay or \#SurvivalDay. DiscoverText's 'deduplication' features were used to refine the dataset to 3,244 unique tweets containing either \#InvasionDay or \#SurvivalDay. Within this set were 628 groups of tweets, each group being 
formed from a distinct tweet and its associated retweets, along with 2,616 single instance tweets. Finally, the \#InvasionDay or \#SurvivalDay dataset was separated into two smaller sub-sets; one containing text only tweets, the second containing a combination of image only and hybrid tweets (i.e. those containing text and images or URLs). The former contains 945 tweets, the latter 2,299 tweets.

For this paper, the smaller set of text-only tweets $(n=945)$ was analysed. The images analysed in the rest of the tweets are not reported here in this paper due to space constraints - many of these images were photos and flags related to the main hashtags studied.

\section{Content Analysis}

An inductive approach was used to identify and code themes within the tweets collected. Coding into categories was dependent on the themes that emerged from within the data. The analysis undertaken involved the researchers manually reading and coding each tweet through a series of iterations until an exhaustive set of categories emerged. The final set of categories was achieved when tweets were coded with only a single code; part of the iterative coding process involved developing new codes and combining others to come up with a way to as closely as possible enable a 1:1 mapping between tweet and code.

The aim of this analysis was to determine what concerns were expressed in an ad-hoc public space scaffolded by \#InvasionDay and \#SurvivalDay, and whether these discussions intersected with the dominant \#AustraliaDay conversation. Individual tweets were coded into one of fifteen categories that emerged from the data, which are explained as follows:

(1) Lessons, tweets that appear sermonistic, encourage learning or attempt to inform about Indigenous rights and/or their experiences with colonisation, or those that call for re-education on the topic of Aboriginal issues.

(2) Co-Opts, tweets which address other debates and controversies tied to events occurring on or around Australia Day not directly related to indigenous issues, largely political in nature; e.g. the Australian Republican debate, knighthoods, asylum seekers and immigration.

(3) Resistance, tweets expressing dissent towards Australia Day events or sentiments, or those that are anti-celebratory in nature.

(4) Lobby, tweets which seek a change of anniversary date for Australia Day, the associated meaning, rituals, or symbolism.

(5) Reflections, tweets which express individual reflections on the meaning of Australia Day or ask questions about related attitudes, behaviours or rituals.

(6) Endorsements, tweets promoting or endorsing another individual or group, tweet, broadcast, media program or event.

(7) Combatants, tweets that are aggressive or antagonistic towards those attempting to insert alternative voices into the dominant \#AustraliaDay discourse. Also, provocative messages showing nationalistic sentiment that excludes or dismisses others, with racial or political prejudice.

(8) Congenialities, tweets that are affable or friendly. Greetings or pleasantries directed either towards individuals or a generic audience.

(9) Apologies, tweets that seek to apologise for Australia's past injustices towards Aboriginal people or recognise Native Title rights. Also, formal acknowledgments of Australia's First people. 
(10) Bonds, tweets offering messages of solidarity, camaraderie, support, or agreement.

(11) Advocates, tweets seeking amends for human rights violations, equality, or social justice.

(12) Reports, tweets providing personal status updates or contributing updates/news on events and activities occurring during the Australia Day holiday.

(13) Comics, tweets of a humorous or satirical nature including those that point out irony in Australia Day sentiments or events.

(14) Fence-sitters, tweets that use the survival day or invasion day hashtags in a neutral, undirected, or tokenistic manner.

(15) Honouring, tweets that express pride in being Australian or calling Australia home. Also declarations of personal pride, Indigenous or non-Indigenous.

\section{Findings and Discussion}

Although the Australia Day Your Way campaign's promotion of \#AustraliaDay was meant to be a laudatory exercise to celebrate Australia Day, the majority of tweets using either \#InvasionDay or \#SurvivalDay (Table 1) were tweets that resisted the mainstream narrative or sought to educate people about the same, hence we found that social media did indeed provide a venue for these alternate narratives and voices. An analysis of the hashtags (Table 2) used also reveals that these surrogate Australia Day hashtags (\#InvasionDay and \#SurvivalDay) dominate an alternate, albeit parallel discourse within the online spaces and the ad-hoc publics created adjacent to the Australia Day Your Way campaign. The percentage values for the Top 2 hashtags, \#InvasionDay (78.94\%) and \#SurvivalDay (33.02\%) was due to 113 tweets $(12 \%)$ that contained both hashtags. A preliminary analysis of the broader dataset reveals similar sentiments across the complete \#InvasionDay or \#SurvivalDay dataset. While 1,164 of the 3,244 tweets contained \#AustraliaDay, an extensive scan of the NMA time capsule could find no discernable presence of either of the hashtags \#SurvivalDay or \#InvasionDay. In the absence of stated selection and curation policy by the NMA in regard to these tweets, except a general statement about 'picking the best [tweets] of the day, which can be viewed online at www.your.australiaday.org.au' it is hard to determine why the tweets with the alternate narrative were excluded. The inclusion of \#AustraliaDay in the tweet should have ensured its collection in the NMA time capsule, standing in protest to the prevailing narrative. While some tweets were directed @NMA in cognizance of their campaign, they did not necessarily make use of the \#AustraliaDay hashtag that would ensure the inclusion of the tweet in the time capsule. Conceivably a deliberate attempt was made by the $29 \%$ of tweets that specifically combined \#AustraliaDay with \#InvasionDay or \#SurvivalDay to appropriate a specific cultural space in an attempt 'to 'take over' and replace current dominant discourse' (Waldner and Dobratz, 2013: 381). The remaining 70\% of tweets however, did not intersect with the dominant conversation, instead remaining isolated and potentially unacknowledged in the NMA time capsule. This time capsule was visible between 2015 and 2017 but has since disappeared from the NMA website. However, the next section details some of these publicly disappeared tweets that we have captured in our data store.

Table 1. Themes of Tweets 


\begin{tabular}{|l|l|l|}
\hline Category & No. of Tweets & Percentage \\
\hline Resistance & 118 & $12.49 \%$ \\
\hline Lessons & 106 & $11.22 \%$ \\
\hline Co-opts & 91 & $9.63 \%$ \\
\hline Lobby & 79 & $8.36 \%$ \\
\hline Reflections & 76 & $8.04 \%$ \\
\hline Endorsements & 66 & $6.98 \%$ \\
\hline Combatants & 65 & $6.88 \%$ \\
\hline Congenialities & 63 & $6.67 \%$ \\
\hline Apologies & 62 & $6.56 \%$ \\
\hline Bonds & 60 & $6.35 \%$ \\
\hline Advocates & 43 & $4.55 \%$ \\
\hline Reports & 42 & $4.44 \%$ \\
\hline Comics & 20 & $3.28 \%$ \\
\hline Fence-sitters & $96.12 \%$ \\
\hline Honouring & $31.95 \%$ \\
\hline Unknown & $63 \%$ & 0.96 \\
\hline
\end{tabular}

Table 2. Top 20 Hashtags

\begin{tabular}{|l|c|c|}
\hline Hashtag & No. of Tweets & Percentage \\
\hline \#InvasionDay & 746 & $78.94 \%$ \\
\hline \#SurvivalDay & 312 & $33.02 \%$ \\
\hline \#AustraliaDay & 274 & $28.99 \%$ \\
\hline \#auspol & 52 & $5.50 \%$ \\
\hline \#ChangeTheDate & 35 & $3.70 \%$ \\
\hline \#StrayaDay & 19 & $2.01 \%$ \\
\hline \#AustraliaDaySoWhite & 15 & $1.59 \%$ \\
\hline
\end{tabular}




\begin{tabular}{|l|c|c|}
\hline \#Australia & 13 & $1.38 \%$ \\
\hline \#canberra & 11 & $1.16 \%$ \\
\hline \#Indigenous & 10 & $1.06 \%$ \\
\hline \#ausday & 9 & $0.95 \%$ \\
\hline \#Genocide & 8 & $0.85 \%$ \\
\hline \#hottest100 & 7 & $0.74 \%$ \\
\hline \#indigenousaustralia & 7 & $0.74 \%$ \\
\hline \#melbourne & 7 & $0.74 \%$ \\
\hline \#Yabun2015 & 7 & $0.74 \%$ \\
\hline \#FiveWordsToRuinAustraliaDay & 6 & $0.63 \%$ \\
\hline \#Jokeknighthood & 6 & $0.63 \%$ \\
\hline \#sorry & 6 & $0.63 \%$ \\
\hline \#straya & 6 & $0.63 \%$ \\
\hline
\end{tabular}

Like graffiti, micro blogging is a form of mediated communication, both occurring across temporal and spatial dimensions rather than face-to-face (Davis, 2000). There are two primary differences between the two phenomena, in that graffiti are generally anonymous and considered illegal in Australia, whereas micro blog texts are identifiable and generally not illegal. Both are unsolicited, and hence it seems both are erased from public view by the authorities in a similar manner. If we accept that social media has transformed cyberspace into 'a shared and lived-in global space that spans most of the world and is influencing many aspects of our lives' (Narayan, 2013: 33) then it is important to acknowledge and explore the possibilities for inequality regimes to be extended beyond traditional temporal and spatial places.

Accepting the assertion that graffiti is discursive action employed by those in our society with limited alternative outlets to express alienation, graffiti research provides a useful model for analysing written expression by marginalised communities in cyberspace. The \#InvasionDay and \#SurvivalDay tweets analysed here support the theory that Twitter stands as a 'wall' on which graffiti can be brought into existence in cyberspace. Producers of the \#InvasionDay and \#SurvivalDay tweets challenged the dominant, celebratory sentiment promoted by the Australia Day Council's Australia Day Your Way initiative, with resistance tweets such as; '\#AustraliaDay is a reminder of the savagery of British \#imperialism which hunted the aborigines as animals \#genocide \#InvasionDay' and 'Today I am not observing 'Australia Day' there is no pride in genocide. \#survivalday \#AustraliaDay \#auspol \#Sovereignty'. 
Those tweets more inclined towards persuasion in their attempts to challenge the dominant narrative include the lobbyists; 'Today is a day of mourning for First Australians. Come on Australia, we can do better \#invasionday \#ChangeTheDate \#AustraliaDay' and ‘@TwitterAU@nma \#ChangeTheDate \#invasionday'.

Hashtags used repeatedly in attempts to get specific topics trending seek to raise the profile of the 'wall'. For example the bond tweets: 'Let's get \#SurvivalDay trending!', 'Would be unreal if we got \#SurvivalDay trending today' and 'Supporting trying to get \#InvasionDay trending in Australia.' Described by Bruns and Burgess as ad hoc issue publics (2011), rapidly evolving hashtag constructed spaces serve to bring a wall into being. Their bottom-up nature however, prevents control of how, once formed, that place is inhabited. The co-opt tweets identified in this study demonstrate acts with which other voices find a platform to colocate their own forms of dissent. As news of the Order of Australia awards are made public, for example, additional issues and conflicts surface. Supporters of an Australian Republic, and those against the knighthood of Prince Phillip, are quickly able to express their own political views with tweets such as 'On our last failed vote on becoming a \#Republic didn't Prince 'Gaff' Phillip say, 'What is wrong with these people?' \#auspol \#SurvivalDay' and 'Small technicality but don't you have to be an Australian citizen to be an Australian knight? \#invasionday'. Similarly, issues such as the treatment of asylum seekers is satirised by the Comics; 'Today we commemorate the history of unauthorised maritime arrivals. Such irony. \#AustraliaDay \#SurvivalDay'.

Chaffee observed that the proliferation of cultural-political graffiti in the Basque region of Spain and France facilitated 'grass-roots participation' (1988: 546) thus enabling graffitists to educate readers about important issues of history and culture. This study identified a crosssection of tweets coded as lessons, which express a desire to experience more equitable conversations and develop more holistic, inclusive historical narratives; 'Rather than mindlessly waving the flag \& saying Happy Australia Day, we encourage ppl 2 listen 2 Indigenous perspectives on \#InvasionDay' and 'Apparently some British still believe Australia was 'discovered' in 1788. The things you learn living in London. \#SurvivalDay'. Tweets categorised as lessons were the most conversational, including the following:

@Elusive_Suasage: 'And here comes the trolls but hey it's not about Hate Fighting Hate, let's educate together and look to a bright future. \#SurvivalDay'

‘@Elusive_Sausage let's all listen to each other \& discuss this. But if we don't have any process we won't make any progress! \#SurvivalDay‘ :@tobyadams80

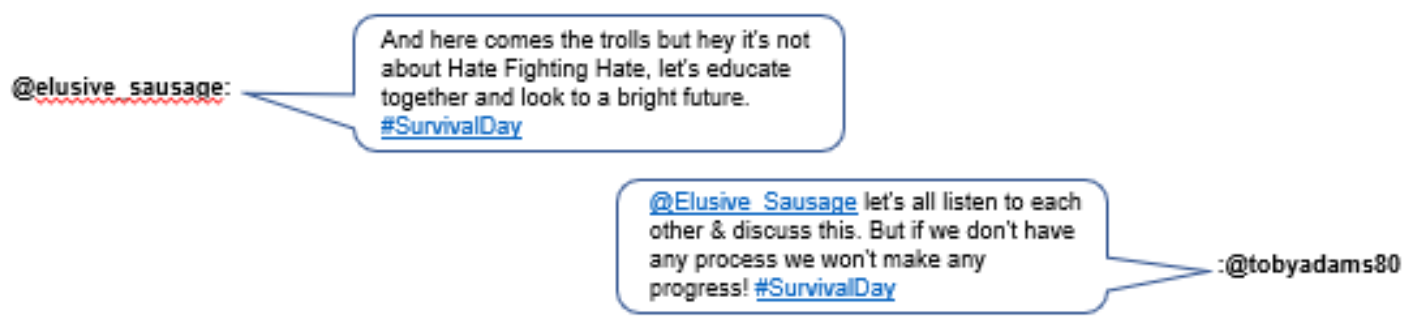



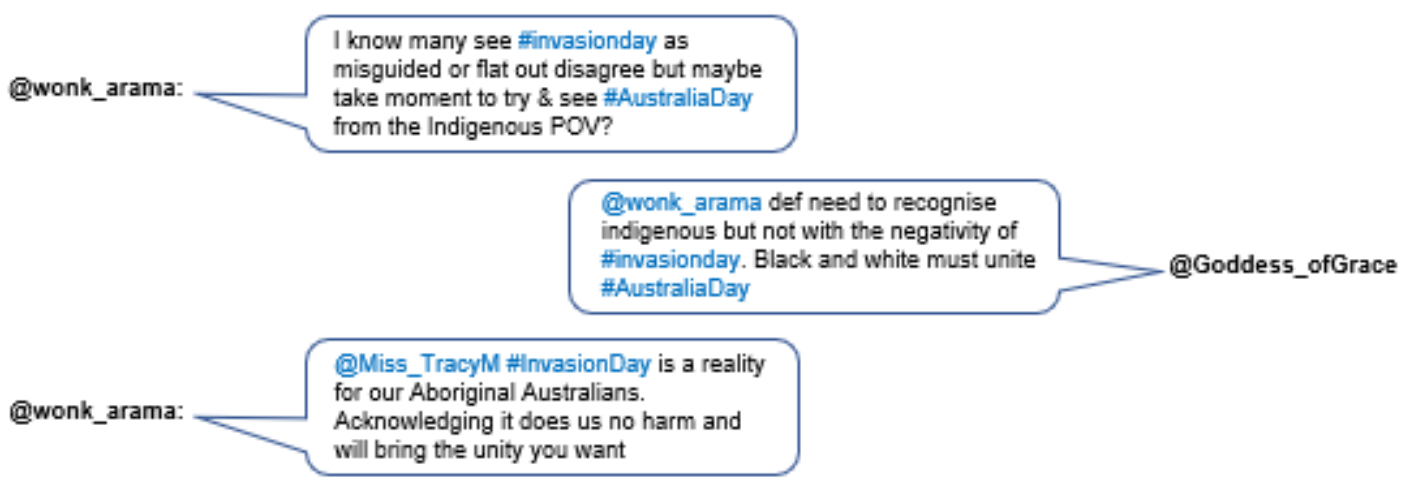

@wonk arama I never claimed

otherwise. But I see that you assumed I _@Miss_TracyM

did

@Miss_TracyM So why won't

acknowledging \#\#nvasionDay help bring

unity? Where's the cost in acknowledging

another's legitimate perspective?

@wonk_arama: 'I know many see \#invasionday as misguided or flat out disagree but maybe take moment to try \& see \#AustraliaDay from the Indigenous POV?'

'@wonk_arama def need to recognise indigenous but not with the negativity of \#invasion day. Black and white must unite \#AustraliaDay': @Goddess_ofGrace

@wonk_arama: ‘@Miss_TracyM \#InvasionDay is a reality for our Aboriginal Australians. Acknowledging it does us no harm and will bring the unity you want'

‘@wonk_arama I never claimed otherwise. But I see that you assumed I did':@Miss_TracyM

@wonk_arama: ‘@Miss_TracyM So whywon't acknowledging \#InvasionDay help bring unity? Where's the cost in acknowledging another's legitimate perspective?'

As observed by Rodriguez and Clair, graffiti is not only used to challenge prevailing narratives, it can be used by one group as an attempt to enforce the oppression of another (1999). In our data, those tweets were categorised as combatant which try to silence the minority voices. For example: 'If the British hadn't of landed in Oz the natives still wouldn't have built a damn thing. \#invasionday? There was nothing to invade' and 'It's not \#invasionday, it's \#enlightenmentday imagine how backward the country wld b if James Cook hadnt dropped in to start enlightenment'.

Accepting meaning to be socially constructed, cyberspace appears to offer opportunities for the engagement that predicates meaning making. At a minimum, it provides the initiator greater visibility of how their unsanctioned texts are received in 'virtual cultural spaces' (McEwan and Sobre-Denton, 2011: 252) over traditional graffiti locales. 
When we consider how the Australia Day Your Way time capsule missed or ignored the majority of the tweets associated with alternative narratives, it raises new questions about capture, preservation, and access to social media as important digital cultural artifacts. In conducting our own data analysis over time, we have observed first hand that access and visibility is particularly transient in cyberspace. As time progresses, an increasing number of tweets are becoming difficult to retrieve, with the original tweet no longer returned; in its place we see text-only representations returned from the Twitter API. As user accounts are switched from public to private or even cancelled, messages such as 'Sorry, that page doesn't exist!', 'Account suspended' and 'Sorry, you are not authorized to see this status', are returned in place of the original tweet. It is conceivable that eventually no original tweets will be returned, thus making Twitter posts as equally ephemeral as graffiti in physical spaces.

In the seven years since Twitter and the Library of Congress announced their partnership to archive and preserve all tweets ever posted, no subsequent news has been forthcoming about their progress to have this data made available to researchers. The challenges associated with managing big data combined with the escalating value of such data to private enterprise, sees access for researchers and the public become ever more cost prohibitive. As per their recent announcement to users, providers such as Texifter are facing huge cost increases for Twitter data access which may potentially force them to discontinue their services (Sifter Administrator, 2017). How will history be told in the future if initial capture is selective and future access is controlled by corporate enterprise?

\section{Conclusion}

In this paper, we have illustrated that social media provides a cultural space in which minority voices do participate and alternate narratives are voiced. We identified the presence of a small but active community clearly contesting the prevailing narrative around a national discourse. There was evidence to demonstrate that minority voices did use an officially sanctioned virtual space to express an alternative discourse. However, this alternate narrative remained adjacent to, but also separate from the dominant one, and was ultimately erased from the mainstream narrative, as it was not represented in the officially curated time capsule available from the National Museum of Australia's website. This can be attributed to curation decisions which favoured one hashtag alone over others employed by minority voices, even when they intersected with the one publicised hashtag. Our data collection process also revealed that access and visibility is particularly transient in cyberspace. Unfortunately, this time capsule is no longer available from the Museum's website, although the authors hold the data that was visible to us at the time and was downloaded/transcribed by us. This transience of online data also makes it particularly important for users attempting to challenge a prevailing narrative to take advantage of hashtag-led conversations when suitable opportunities arise, but also to think about how these conversations are captured and archived (or not archived), either by themselves or by cultural institutions.

The lack of \#InvasionDay and \#SurvivalDay hashtags in the public record at the National Museum of Australia also raises new questions regarding the curation of a nation's digital cultural heritage. While it may be difficult for any particular institution to 'dominate the conversation' (Bruns and Burgess, 2011: 7) they retain a position of power in which to wipe clean from view or select narratives from those expressed. The Australian Prime Minister 
tweeted a week before Australia Day 2018, 'A free country debates its history, it does not deny it' (Turnbull, 2018). However, this statement was immediately followed by another, which clearly counteracted the first, and explained 'Australia Day is Australia's day - a day when we come together and celebrate our nation and all of its history' (Turnbull, 2018), presumably with no dissent either encouraged or acknowledged.

Our study clearly illustrates the issues discussed in the literature about selection and access of digital materials, whilst also highlighting the ethical issues involved, as described by Ravenwood, Matthews, and Muir (2013). In light of our findings, it is important for LIS practitioners to reflect upon the question: How do cultural heritage institutions such as libraries, archives and museums implement professional practices to ensure continued access to the digital artefacts of modern society without any selection bias?

\section{Acknowledgements}

This work was made possible through the support of the Australian Government Research Training Program Scholarship.

\section{Funding}

The author(s) received no financial support for the research, authorship, and/or publication of this article.

\section{Author Bios}

Pamela Fransen-Taylor is a doctoral candidate in the School of Communication at the University of Technology Sydney (UTS), Sydney, Australia. Pamela has a Master of Arts in Information and Knowledge Management and a Bachelor of Applied Science in Information Studies, both from UTS. Her research interests include information behaviour, social media and utilising the Internet to support and build social capital. She can be contacted at Pamela.Fransen-Taylor@uts.edu.au

Dr Bhuva Narayan is a Senior Lecturer at the School of Communication at the University of Technology Sydney (UTS), Sydney, NSW 2007, Australia. Her research interests include information behaviour, user experience, human learning, and design thinking. She can be contacted at Bhuva.Narayan@uts.edu.au

\section{References}

Abel EL and Buckley BE. (1977) The handwriting on the wall: Toward a sociology and psychology of graffiti. Westport, CT: Greenwood Press.

Acker A and Kriesberg A. (2017) Tweets may be archived: Civic engagement, digital preservation and obama white house social media data. Proceedings of the Association for Information Science and Technology 54(1): pp. 1-9.

Acker J. (2006) Inequality regimes gender, class, and race in organizations. Gender \& Society 20(4): 441-464 
Alaimo K. (2017) All tweets belong in the Library of Congress. Available at: http://edition.cnn.com/2017/12/27/opinions/library-of-congress-should-keep-alltweets-opinion-alaimo/index.html (acccessed 21 January 2018).

Arnold T and Sampson W. (2014) Preserving the Voices of Revolution: Examining the creation and preservation of a subject-centered collection of tweets from the Eighteen Days in Egypt. The American Archivist 77(2): 510-533.

Aslam S. (2018) Twitter Statistics. Available at: https://www.omnicoreagency.com/twitterstatistics/ (accessed 21 January 2018).

Australian Bureau of Statistics. (2006) Cultural diversity overview. Available at: http://www.ausstats.abs.gov.au/ausstats/subscriber.nsf/LookupAttach/2070.0Publicati on29.01.0910/\$File/20700_Cultural_overview.pdf (accessed 4 February 2018).

Australian Bureau of Statistics. (2011) 2076.0 Census of Population and Housing: Characteristics of Aboriginal and Torres Strait Islander Australians, 2011. Available at:

http://www.abs.gov.au/AUSSTATS/abs@.nsf/DetailsPage/2076.02011?OpenDocume nt (accessed 4 February 2018).

Australian Electoral Commission. (2012) 1999 Referendum Report and Statistics. Available at:

http://www.aec.gov.au/Elections/referendums/1999_Referendum_Reports_Statistics/ (accessed 26 September 2017).

Australian Government. (2015) Order of Australia. Available at: http://www.itsanhonour.gov.au/honours/awards/medals/order_of_australia.cfm (accessed 27 May 2015).

Bode L, Hanna A, Yang J, et al. (2015) Candidate Networks, Citizen Clusters, and Political Expression Strategic Hashtag Use in the 2010 Midterms. The ANNALS of the American Academy of Political and Social Science 659(1): 149-165.

Bowen T. (2010) Reading gestures and reading codes: The visual literacy of graffiti as both physical/performative act and digital information text. Mapping Minds. Oxford: InterDisciplinary Press, pp. 85-93.

boyd, danah and Ellison NB. (2008) Social network sites: Definition, history, and scholarship. Journal of Computer- Mediated Communication 13(1): 210-230.

Bruns A. (2018) The Library of Congress Twitter Archive: A Failure of Historic Proportions. QUT Social Media Research Group. Available at:

http://socialmedia.qut.edu.au/2018/01/02/the-library-of-congress-twitter-archive-afailure-of-historic-proportions/ (accessed 8 January 2018).

Bruns A and Burgess J. (2015) Twitter hashtags from ad hoc to calculated publics. In Hashtag publics: The power and politics of discursive networks. New York: Peter Lang, pp. 13-28.

Bruns A and Burgess JE. (2011) The use of Twitter hashtags in the formation of ad hoc publics. In Proceedings of the 6th European Consortium for Political Research (ECPR) General Conference 2011. University of Iceland, Reykjavik.

Bryman A. (2012) Social Research Methods. Oxford University Press.

Chaffee L. (1988) Social conflict and alternative mass communications: public art and politics in the service of Spanish- Basque nationalism. European Journal of Political Research 16(5): 545-572.

Darian-Smith, K. (2018). Australia Day, Invasion Day, Survival Day: a long history of celebration and contestation. [online] The Conversation. Available at: https://theconversation.com/australia-day-invasion-day-survival-day-a-long-historyof-celebration-and-contestation-70278 [Accessed 5 Feb. 2018]. 
Davis JE. (2000) Identity and Social Change, New Brunswick, N. J.: Transaction Publishers. Deodato J. (2014) The patron as producer: libraries, web 2.0, and participatory culture. Journal of Documentation 70(5): 734-758.

Dockery AM. (2010) Culture and wellbeing: The case of Indigenous Australians. Social Indicators Research 99(2): 315-332.

Evens T and Hauttekeete L. (2011) Challenges of digital preservation for cultural heritage institutions. Journal of Librarianship and Information Science 43(3): 157-165.

Fransen-Taylor P and Narayan B. (2016) \#Homeless but at home in cyberspace. Information Research, 21(4): 1-16.

Gadsby JM. (1995) Looking at the writing on the wall: A critical review and taxonomy of graffiti texts. Available at: http://sunsite.icm.edu.pl/graffiti/faq/critical.review.html (accessed on 16 May 2015)

Giglietto F and Lee Y. (2017) A hashtag worth a thousand words: Discursive strategies around \#JeNeSuisPasCharlie after the 2015 Charlie Hebdo shooting. Social Media+ Society 3(1): 1-15.

Gurstein M. (2003) Effective use: A community informatics strategy beyond the digital divide. First Monday 8(12).

Hanauer DI. (2011) The discursive construction of the separation wall at Abu Dis: Graffiti as political discourse. Journal of Language \& Politics 10(3): 301-321.

Henninger M and Scifleet P. (2016) How are the new documents of social networks shaping our cultural memory. Journal of Documentation 72(2): 277-298.

Jones FL. (2000) Diversities of national identity in a multicultural society: The Australian case. National Identities 2(2): 175-186.

Kaplan AM and Haenlein M. (2010) Users of the world, unite! The challenges and opportunities of Social Media. Business Horizons 53(1): 59-68.

Koepfler JA and Hansen DL. (2012) We are visible: technology-mediated social participation in a Twitter network for the homeless. In Proceedings of the 2012 iConference. Toronto, ON, Canada, 7-10 February 2012, pp. 492-493. ACM.

Kwak H, Lee C, Park H, et al. (2010) What is Twitter, a social network or a news media? In Proceedings of the 19th international conference on World wide web, Raleigh, North Carolina, 26-30 April 2010, pp. 591-600. ACM.

Leetaru K. (2017) The Library Of Congress In the Digital Age: From Archiving Twitter To Innovation Lab. Available at: https://www.forbes.com/sites/kalevleetaru/2017/12/28/the-library-of-congress-in-thedigital-age-from-archiving-twitter-to-innovation-lab/\#45913ff51e87 (accessed 21 January 2018)

Lim M. (2012) Clicks, cabs, and coffee houses: Social media and oppositional movements in Egypt, 2004-2011. Journal of Communication 62(2): 231-248.

Macquarie Dictionary. (1995) The Macquarie Encyclopedic Dictionary. Sydney: Macquarie Library Pty Ltd.

McEwan B and Sobre-Denton M. (2011) Virtual cosmopolitanism: Constructing third cultures and transmitting social and cultural capital through social media. Journal of International and Intercultural Communication 4(4): 252-258.

Mehra B, Merkel C and Bishop AP. (2004) The internet for empowerment of minority and marginalized users. New Media \& Society 6(6): 781-802.

Moorley CR and Chinn T. (2014) Nursing and Twitter: Creating an online community using hashtags. Collegian 21(2): 103-109. 
Narayan B. (2013) Social media use and civil society: From everyday information behaviours to clickable solidarity. Cosmopolitan Civil Societies: An Interdisciplinary Journal 5(3): 32-53.

National Australia Day Council (2015a) 1988: The Bicentenary. Available at: http://www.australiaday.org.au/australia-day/history/1988-the-bicentenary/ (accessed 17 April 2015).

National Australia Day Council (2015b) About our National Day. Available at: http://www.australiaday.org.au/australia-day/about-our-national-day/ (accessed 17 April 2015).

National Australia Day Council (2015c) Beginnings. Available at: http://www.australiaday.org.au/australia-day/history/beginnings/(accessed 17 April 2015).

Naughton J. (2001) Contested space: the internet and global civil society. In: Anheier H, Glasius M and Kaldor M (eds) Global Civil Society 2001. Oxford University Press, pp. 147-168.

Onyx J, Ho C, Edwards M, et al. (2011) Scaling up connections: Everyday cosmopolitanism, complexity theory \& social capital. Cosmopolitan Civil Societies: An Interdisciplinary Journal 3(3): 47-67.

Osterberg G. (2017) Update on the Twitter Archive at the Library of Congress. Available at: https://blogs.loc.gov/loc/2017/12/update-on-the-twitter-archive-at-the-library-ofcongress-2/?loclr=twloc (accessed on 9 January 2018).

Peteet J. (1996) The writing on the walls: The graffiti of the Intifada. Cultural Anthropology 11(2): 139-159.

Pettigrew KE. (1999) Waiting for chiropody: contextual results from an ethnographic study of the information behaviour among attendees at community clinics. Information Processing \& Management 35(6): 801-817.

Ravenwood C, Matthews G and Muir A. (2013) Selection of digital material for preservation in libraries. Journal of Librarianship and Information Science 45(4): 294-308.

Ravenwood C, Muir A, Matthews G. (2015) Stakeholders in the selection of digital material for preservation: Relationships, responsibilities, and influence. Collection Management, 40: (2): 83-110.

Rodriguez A and Clair RP. (1999) Graffiti as communication: Exploring the discursive tensions of anonymous texts. Southern Journal of Communication 65(1): 1-15.

SalahEldeen H and Nelson M. (2012) Losing my revolution: How many resources shared on social media have been lost? In International Conference on Theory and Practice of Digital Libraries, Paphos, Cyprus, 23-27 September 2012, pp. 125-137. Berlin: Springer.

Scheibel D. (1994) Graffiti and "film school" culture: Displaying alienation. Communications Monographs 61(1): 1-18.

Scifleet P, Henninger M and Albright KH. (2013) When social media are your source. Information Research 18(3) paper C41. Available at: www.informationr.net/ir/183/colis/paperC41.html (accessed on 9 January 2018).

Shirky C. (2011) The political power of social media: Technology, the public sphere, and political change. Foreign affairs 90(1): 28-41.

Shulman S. (2018) Big News From the Library of Congress. Available at: https://discovertext.com/2017/12/28/big-news-from-the-library-of-congress/ (accessed on 14 January 2018).

Siapera E. (2014) Tweeting\# Palestine: Twitter and the mediation of Palestine. International Journal of Cultural Studies 17(6): 539-555. 
Sifter Administrator (2017) Potential discontinuation of Sifter service for Historical Twitter Data [email]

Snowden, C. (2015). No, Tony Abbott, you can't dismiss social media as 'electronic graffiti'. [online] The Conversation. Available at: https://theconversation.com/no-tony-abbottyou-cant-dismiss-social-media-as-electronic-graffiti-36819 [Accessed 5 Feb. 2018].

Stocker TL, Dutcher LW, Hargrove SM, Cook EA. (1972) Social Analysis of Graffiti. Journal of American Folklore 85(338): 356-366.

squig (2015) '\#electronicgraffiti is real democracy; people working together for the common good; poison to vermin like Abbott. \#SurvivalDay' 26 January, Twitter post, viewed 6 February 2018 at https://twitter.com/squig_/status/559552026489536515

Trottier D. (2011) A Research Agenda for Social Media Surveillance. Available at: https://www.uta.edu/huma/agger/fastcapitalism/8_1/trottier8_1.html (accessed on 1 August 2017).

Tufekci Z and Wilson C. (2012) Social media and the decision to participate in political protest: Observations from Tahrir Square. Journal of Communication 62(2): 363-379.

Tuominen K and Savolainen R. (1997) A social constructionist approach to the study of information use as discursive action. In Proceedings of an International Conference on Information Seeking in Context. Tampere, Finland, 14-16 August, 1996, pp. 81-96. Taylor Graham Publishing.

Turnbull Malcolm (2018) 'A free country debates its history, it does not deny it. Australia Day is Australia's day - a day when we come together and celebrate our nation and all of its history.' 15 January, Twitter post, viewed 6 February 2018 at https://twitter.com/TurnbullMalcolm/status/952796048228892672

Veinot TC and Williams K. (2012) Following the "community" thread from sociology to information behavior and informatics: Uncovering theoretical continuities and research opportunities. Journal of the American Society for Information Science and Technology 63(5): 847-864

Waldner LK and Dobratz BA. (2013) Graffiti as a form of contentious political participation. Sociology Compass 7(5): 377-389.

Weaver M. (2007) Contextual metadata: faceted schemas in virtual library communities. Library Hi Tech 25(4): 579-594.

Whitehead JL. (2004) Graffiti: The Use of the Familiar. Art Education 57(6): 25-32.

Zappavigna M. (2011) Ambient affiliation: A linguistic perspective on Twitter. New Media \& Society 13(5): 788-806. 